\title{
Differences in Early Gesture Explain SES Disparities in Child Vocabulary Size at School Entry
}

\section{Citation}

Rowe, M. L., and S. Goldin-Meadow. 2009. “Differences in Early Gesture Explain SES Disparities in Child Vocabulary Size at School Entry." Science 323 (5916) (February 13): 951-953. .

\section{Published Version}

doi:10.1126/science.1167025

\section{Permanent link}

http://nrs.harvard.edu/urn-3:HUL.InstRepos:13041217

\section{Terms of Use}

This article was downloaded from Harvard University's DASH repository, and is made available under the terms and conditions applicable to Other Posted Material, as set forth at http:// nrs.harvard.edu/urn-3:HUL.InstRepos:dash.current.terms-of-use\#LAA

\section{Share Your Story}

The Harvard community has made this article openly available.

Please share how this access benefits you. Submit a story.

Accessibility 


\section{Science \\ MIAAAS}

Differences in Early Gesture Explain SES Disparities in Child Vocabulary Size at School Entry

Meredith L. Rowe, et al.

Science 323, 951 (2009);

DOI: $10.1126 /$ science.1167025

The following resources related to this article are available online at www.sciencemag.org (this information is current as of February 16, 2009 ):

Updated information and services, including high-resolution figures, can be found in the online version of this article at:

http://www.sciencemag.org/cgi/content/full/323/5916/951

Supporting Online Material can be found at:

http://www.sciencemag.org/cgi/content/full/323/5916/951/DC1

This article appears in the following subject collections:

Education

http://www.sciencemag.org/cgi/collection/education

Information about obtaining reprints of this article or about obtaining permission to reproduce this article in whole or in part can be found at:

http://www.sciencemag.org/about/permissions.dtl 
A. Van de Poel, M. De Raeymaeker, K. Thys,

J. Vandersmissen, ]. van der Schueren, R. Brown,

K. Albert, V. Coose, K. Pittois, S. Theunissen, V. Hendrix

E. Maes, K. Craessaerts, ]. Prennen, A. Deelder,

P. Scheltens, and M. Mercken. We are grateful to

G. Vassart and C. Ledent (Université Libre de Bruxelles, Brussels, Belgium) for the RT-GPR3 and RT-TSHr cDNA and assistance with CAMP assays, C. H. Berlot (Geisinge Medical Center, Danville, PA) for the $\mathrm{G}_{s} \mathrm{DN}$ and R280K cDNA, and Murat Bastepe (Harvard Medical School,
Boston, MA) for the $G_{s \alpha}$-null mouse embryo fibroblasts. This project was supported by IWT990363, IWT010512. and IWT030623, a Methusalem grant from the Flemish government, the Fund for Scientific Research (Flanders, Belgium), and the Federal Office for Scientific Affairs (IUAP P6/43/), Belgium. B.D.S. has been a paid consultant for Galapagos, a drug discovery company. Galapagos holds U.S. patent 7429459 on the GPR3 findings and the technology and library used in this study.
Supporting Online Material

www.sciencemag.org/cgi/content/full/323/5916/946/DC1

Materials and Methods

SOM Text

Figs. S1 to S14

Tables $\mathrm{S} 1$ to $\mathrm{S5}$

References

19 May 2008; accepted 19 December 2008

10.1126/science. 1160649

\section{Differences in Early Gesture Explain SES Disparities in Child Vocabulary Size at School Entry}

\author{
Meredith L. Rowe* and Susan Goldin-Meadow
}

Children from low-socioeconomic status (SES) families, on average, arrive at school with smaller vocabularies than children from high-SES families. In an effort to identify precursors to, and possible remedies for, this inequality, we videotaped 50 children from families with a range of different SES interacting with parents at 14 months and assessed their vocabulary skills at 54 months. We found that children from high-SES families frequently used gesture to communicate at 14 months, a relation that was explained by parent gesture use (with speech controlled). In turn, the fact that children from high-SES families have large vocabularies at 54 months was explained by children's gesture use at 14 months. Thus, differences in early gesture help to explain the disparities in vocabulary that children bring with them to school.

$\mathrm{I}$ has long been recognized that children from high-socioeconomic status (SES) families have, on average, larger vocabularies than children from low-SES families (1). This SES gap in vocabulary size begins in the toddler years (2), widens until age four, and then remains relatively constant throughout the school years (3). Vocabulary is a key predictor of school success (4) and is a primary reason why low-SES children enter school at greater risk for failure than their high-SES peers (5). Early childhood is thus a critical educational period, as SES differences in language skills first emerge during these years $(3,6)$.

What is it about a family's SES that leads to disparities in child vocabulary? Previous research suggests that the way parents talk to their children explains some of the relation between SES and child vocabulary (1, 7-9). On average, parents from higher-SES groups talk more, use more diverse vocabulary, and use more complex syntax with their children than parents from lowerSES groups, and these differences relate to child vocabulary development $(2,7,8,10-13)$.

Here we investigate another aspect of parentchild communication in relation to SES - parent and child gesture use. We know that children gesture to communicate before they use speech $(14,15)$. Further, there is a positive relation be-

Department of Psychology, University of Chicago, 5848 South University Avenue, Chicago, IL 60637, USA.

*To whom correspondence should be addressed. E-mail: rowemer@uchicago.edu tween parent gesture and child gesture (16-19), and early child gesture predicts later child vocabulary, even controlling for early child speech $(16,20)$. We build on this earlier work and ask: Are there SES differences in the way children and their parents use gesture? If so, might these differences help to explain the robust relation between SES and child vocabulary skill?

To address these questions, we videotaped 14-month-old children from 50 families (representing the demographic range of the Chicago area) engaging in their ordinary activities with their primary caregivers at home for $90 \mathrm{~min}$. We and child during the interaction to glean measures of spoken vocabulary and gesture use [see the supporting online material (SOM) for details on sample and coding].

The number of "gesture types," defined as the number of different meanings conveyed by gesture, served as our measure of child and parent gesture use (e.g., pointing at a $\operatorname{dog}=\operatorname{dog}$ ). Previous research has found child gesture types, rather than child gesture frequency, to be a better predictor of later-child spoken vocabulary size (16). At 14 months, children produced an average of 20.6 gesture types $(\mathrm{SD}=11.9)$, and parents produced an average of 39.3 gesture types $(\mathrm{SD}=25.6)$.

The number of "word types," defined as the number of different intelligible word roots produced by the speaker, served as our measure of spoken vocabulary. At 14 months, children used an average of 13 word types during the intertranscribed all speech and gesture used by parent action ( $\mathrm{SD}=13.3)$, and parents used an average of 364 word types $(\mathrm{SD}=132.0)$.

At child age 14 months, there was a positive relation between spoken word types and gesture types for both children (correlation coefficient $r=0.61, P<0.001)$ and parents $(r=0.67, P<$ $0.001)$. Furthermore, parents who produced more gesture types had children who produced more gesture types $(r=0.44, P<0.001)$. However, there was no relation between parent word types and child word types at this early stage of language production, nor was there a relation between parent word types and child gesture types.

On average, parents had 15.8 years of education $(\mathrm{SD}=2.2)$ and an average family income level of $\$ 60,400(\mathrm{SD}=\$ 31,365)$. Family income and education were positively related to one another $(r=0.44, P=0.001)$ and were combined into one variable (SES) with the use of principal components analysis (see the SOM for more information on SES measures).

SES was positively related to child gesture at 14 months $(r=0.30, P<0.05)$ and to parent gesture at child age 14 months $(r=0.45, P=$ 0.001). Thus, SES differences are reflected in early parent-child gesture use. However, there was no relation between SES and child word types, although there was a positive relation between SES and parent word types $(r=0.44, P=$ 0.001).

We used correlation and regression analyses to determine whether the positive relation between SES and children's early gesture use is mediated by parents' gesture use during interactions with their children. We followed guidelines for evaluating mediation models put forth by Baron and Kenny (21). Specifically, we used statistics to determine whether one variable explains a significant amount of the relation found between two other variables (see the SOM for more information on mediation analysis and assumptions).

The three scatter plots presented in the top of Fig. 1 show that the first three necessary conditions for mediation were met. The leftmost panel presents (i) the significant relation between the predictor variable (SES) and the outcome variable (child gesture). The middle panel displays (ii) the significant relation between the predictor variable (SES) and the potential mediator variable (parent gesture). The rightmost panel displays (iii) the significant relation between the mediator variable (parent gesture) and the outcome variable (child gesture). The 
fourth and final necessary condition for mediation is that the significant relation between the predictor variable (SES) and the outcome variable (child gesture) must be reduced when the mediator variable (parent gesture) is included in the model. This effect is shown in the bottom portion of Fig. 1: (iv) The relation between SES and child gesture (controlling for children's word types at 14 months) is no longer significant when parent gesture is included in the model - the parameter estimate for the SES effect reduces to 1.85 (from 3.45). Bootstrapping procedures to test the significance of this indirect effect (i.e., the product of the coefficients that make up the mediated effect) $(22,23)$ gave a $95 \%$ confidence
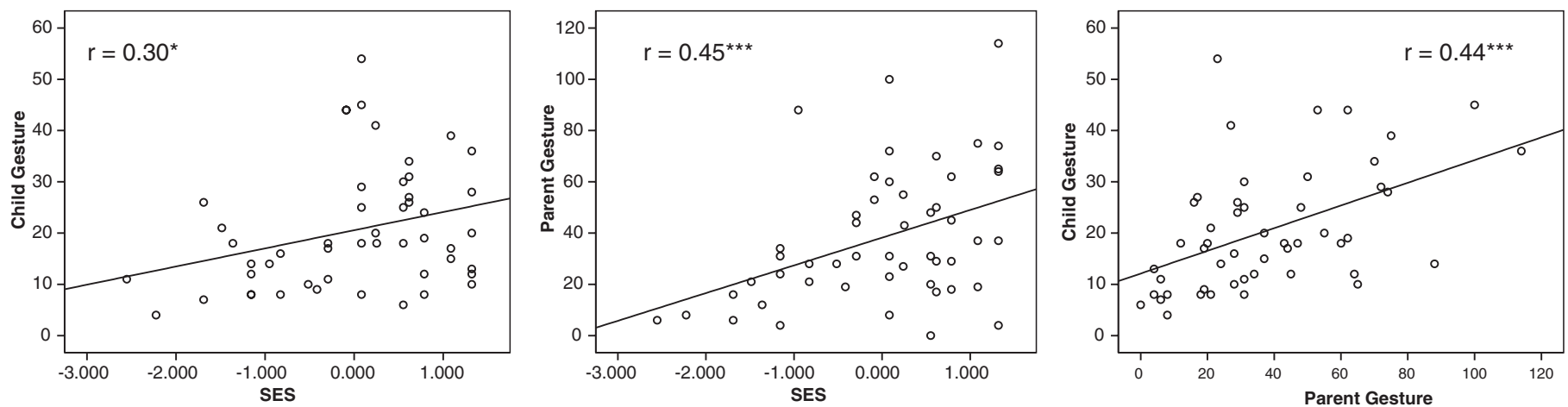

Fig. 1. Scatter plots showing relations between (i) SES and child gesture at 14 months (top left), (ii) SES and parent gesture at child age 14 months (top middle), and (iii) parent gesture and child gesture (top right). The bottom portion of the figure represents analysis (iv) showing that parent gesture mediates the relation between SES and child gesture, controlling for child speech at 14 months $(n=50$ children). Taken together, SES and child speech explain $45 \%$ of the variation in child gesture; adding parent gesture explains $52 \%$. Asterisks indicate the level of statistical significance as noted; $\beta$ indicates the regression parameter estimate; ns, not significant (at the

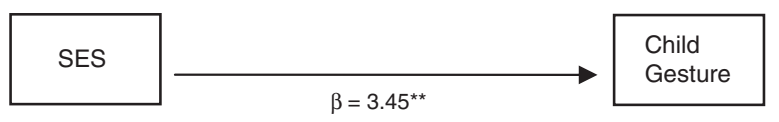
$P<0.05$ (evel).
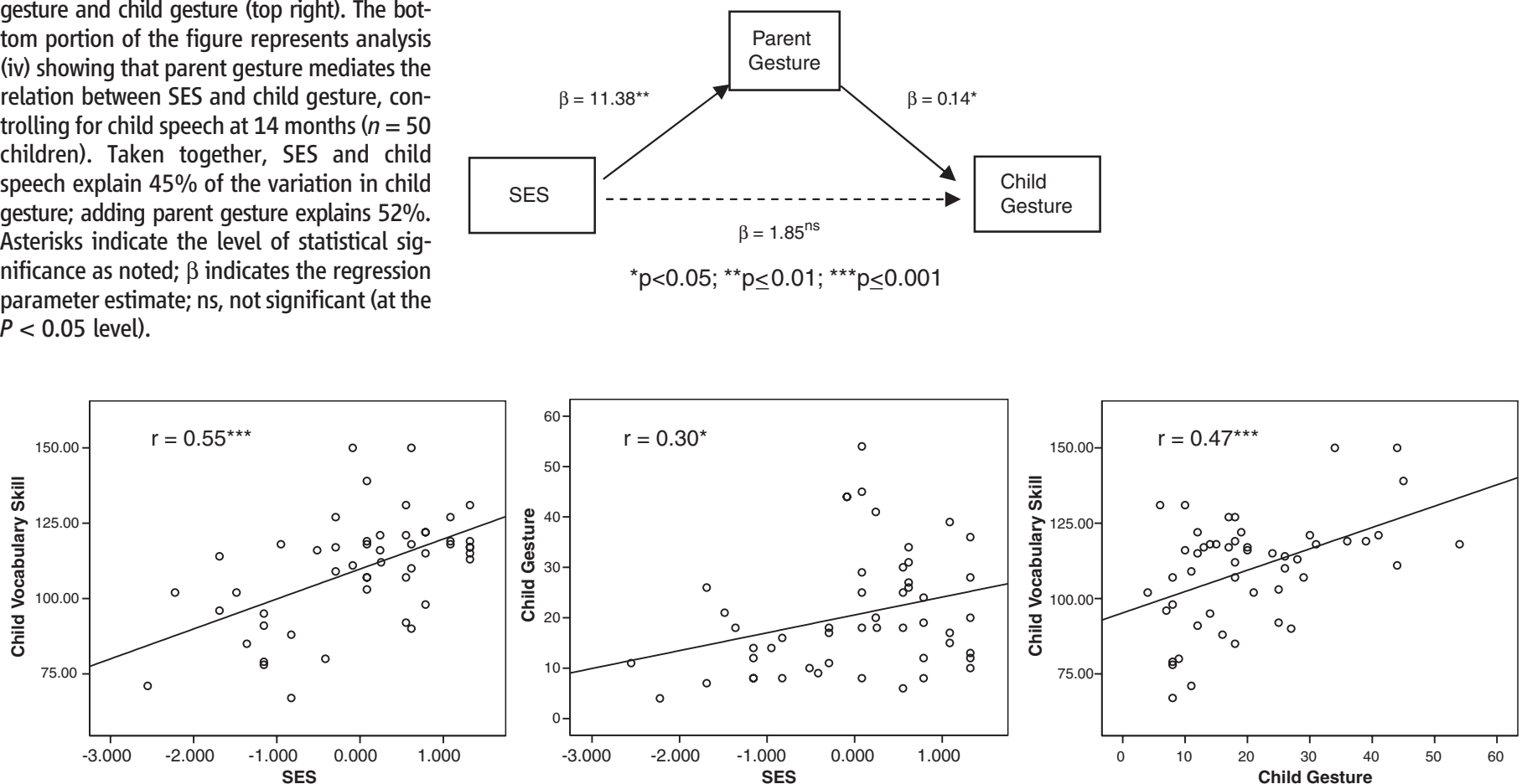

Fig. 2. Scatter plots showing relations between (i) SES and child vocabulary skill (PPVT) at 54 months (top left), (ii) SES and child gesture at 14 months (top middle), and (iii) child gesture and child vocabulary skill (top right). The bottom portion of the figure represents analysis (iv) showing that child gesture mediates the relation between SES and child vocabulary skill, controlling for child speech at 14 months ( $n=50$ children). Taken together, SES and child speech explain 33\% of the variation in child vocabulary skill; adding child gesture explains $40 \%$.

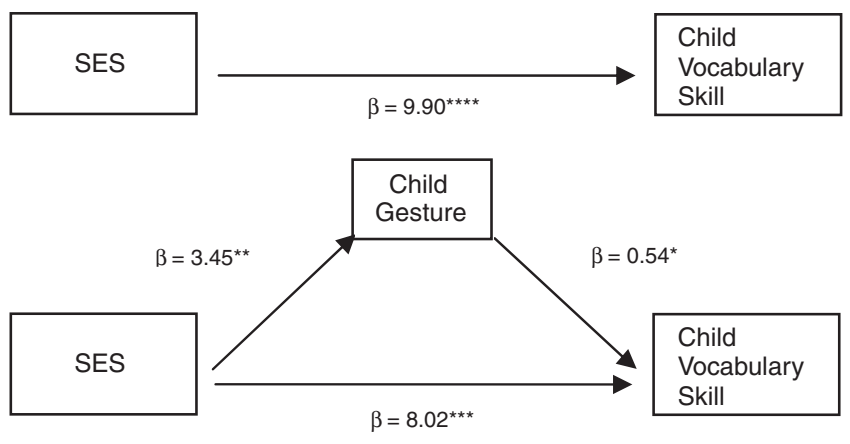

${ }^{*} p<0.05 ;{ }^{* *} p \leq 0.01 ;{ }^{* * *} p \leq 0.001$ 
interval (corrected for bias) of 0.26 to 3.52 , an interval that does not contain zero and thus indicates that the mediation effect is significant.

We ran an additional model including parent word types at child age 14 months. In this model, parent gesture and child word types remained significant predictors of child gesture, but neither SES nor parent word types were significant predictors. Thus, the relation between parent gesture and child gesture holds even with parent talk controlled.

We now ask whether the relation between SES and later child vocabulary skill can be explained by children's early gesture use. We assessed child vocabulary skill at 54 months with the use of the Peabody Picture Vocabulary Test (PPVT) (24). The average normed PPVT score for the sample was 109.8 $(\mathrm{SD}=18.1)$. The scatter plots in Fig. 2 show that the first three conditions of mediation are met: (i) SES relates to children's PPVT scores, $r=0.55, P<0.001$ (leftmost panel); (ii) SES relates to child gesture, $r=0.30$, $P<0.05$ (middle panel); and (iii) child gesture relates to PPVT scores, $r=0.47, P=0.001$ (rightmost panel). The bottom portion of Fig. 2 shows the results of the mediation analysis. (iv) The relation between SES and PPVT (controlling for children's word types at 14 months) reduces in magnitude when child gesture is included in the model; the parameter estimate for the SES effect reduces to 8.02 (from 9.90). Bootstrapping procedures gave a $95 \%$ confidence interval (corrected for bias) of 0.44 to 4.51 , an interval that does not contain zero and thus indicates that the mediation effect is significant. Thus, the effect of SES on child vocabulary at 54 months is mediated, in part, by children's gesture use at 14 months.

Overall, our findings are consistent with the following developmental history. When interacting with their children, parents from higher-SES groups use gesture to communicate a broader range of meanings than parents from lower-SES groups. By 14 months, children from these higherSES families are using gesture to communicate more meanings than children from lower-SES families. Thus, as early as 14 months of age, children in different SES groups may be socialized to communicate more or fewer meanings via gesture. These early differences in gesture, in turn, help to explain the large disparities in vocabulary size that characterize children of different SES groups at school entry.

It is notable that, in the initial stages of language learning when SES differences in children's spoken vocabulary are not yet evident, we see SES differences in child gesture use. Children typically do not begin gesturing until around 10 months of age $(14,15)$. Thus, SES differences are evident a mere 4 months (and possibly even sooner) after the onset of child gesture production.

Why do we see SES differences in children's early gestures? Although correlation does not imply causation or the direction of effects, our results implicate parent gesture as a plausible mechanism. Even before they produce their own gestures, children comprehend the gestures that others produce $(25,26)$. Because children from high-SES backgrounds are exposed to a broader range of meanings in gesture than children from lower-SES backgrounds (as shown here), they themselves are likely to produce more meanings in gesture, which then promotes the development of more vocabulary words in speech (27). This scenario parallels findings in speech - children from high-SES backgrounds are exposed to more diverse vocabulary than children from lower-SES backgrounds and, in turn, produce more vocabulary words of their own $(2,12)$. Thus, SES appears to relate to child vocabulary in two ways: (1) through parent speech and (2) through parent and child gesture.

We have shown here that variation in children's early gesture use, independent of early spoken vocabulary, explains a portion of the robust relation between SES and later vocabulary skill. However, the specific nature of the relation between early child gesture and later child vocabulary is not addressed in this study. Child gesture could play an indirect role in word learning by eliciting timely speech from parents; for example, in response to her child's point at a doll, a mother might say, "yes, that's a doll," thus providing a word for the object that is the focus of the child's attention. S. Goldin-Meadow et al. (28) found that when mothers "translated" their child's gestures into words in just this way, those words tended to become part of the child's spoken vocabulary several months later. Gesture could also play a more direct role in word learning by giving children an opportunity to practice generating particular meanings by hand, at a time when those meanings are difficult to produce by mouth (27).

Whether or not early gesture plays a direct or indirect role in word learning, it is clear that gesturing partially accounts for the relation between SES and later vocabulary skill. Of course, gesture is not the sole factor mediating the robust relation between SES and child vocabulary. Other environmental factors (including parent speech) and child factors probably influence child vocabulary as well. Nonetheless, given our findings, it seems fruitful for future research to explore whether parents and children can be encouraged to increase the rate at which they spontaneously gesture when they speak [as has been shown in older children, either by directly telling them to gesture (29) or by modeling gesture for them (30)]. If so, the next step is to explore whether increases in gesturing lead to vocabulary gains in early childhood.

\section{References and Notes}

1. E. Hoff, Dev. Rev. 26, 55 (2006).

2. B. Hart, T. Risley, Meaningful Differences in the Everyday Experience of Young American Children (Brookes, Baltimore, 1995).

3. G. Farkas, K. Beron, Soc. Sci. Res. 33, 464 (2004).

4. R. C. Anderson, P. Freebody, in Reading Comprehension and Education, ]. T. Guthrie, Ed. (International Reading Association, Newark, DE, 1981), pp. 77-117.
5. C. E. Snow, S. Burns, P. Griffin, Preventing Reading Difficulties in Young Children (National Academy, Washington, DC, 1998).

6. G. J. Duncan, W. J. Yeung, ]. Brooks-Gunn, ]. R. Smith, Am. Sociol. Rev. 63, 406 (1998)

7. E. Hoff, in Socioeconomic Status, Parenting, and Child Development, M. H. Bornstein, Ed. (Erlbaum, Mahwah, N], 2003), pp. 147-160.

8. E. Hoff, Child Dev. 74, 1368 (2003).

9. E. Hoff, B. Laursen, T. Tardiff, in Handbook of Parenting, Volume Il: Ecology and Biology of Parenting, M. H. Bornstein, Ed. (Erlbaum, Mahwah, N], 2003), pp. 161-188.

10. M. H. Bornstein, M. O. Haynes, K. M. Painter, J. Child Lang. 25, 367 (1998).

11. S. B. Heath, in Cultural Psychology: Essays on Comparative Human Development, ]. W. Stigler, R. A. Shweder, G. Herdt, Eds. (Cambridge Univ. Press, Cambridge, 1990), pp. 496-519.

12. ]. Huttenlocher, M. Vasilyeva, H. R. Waterfall, ]. L. Vevea, L. V. Hedges, Dev. Psychol. 43, 1062 (2007).

13. B. A. Pan, M. L. Rowe, J. D. Singer, C. E. Snow, Child Dev. 76, 763 (2005)

14. E. Bates, Language and Context (Academic, Orlando, FL, 1976).

15. E. Bates, L. Benigni, I. Bretherton, L. Camaioni, V. Volterra, The Emergence of Symbols: Cognition and Communication in Infancy (Academic, New York, 1979).

16. M. L. Rowe, S. Özçalıskan, S. Goldin-Meadow, First Lang. 28, 182 (2008)

17. M. L. Rowe, First Lang. 20, 305 (2000).

18. J. M. Iverson, O. Capirci, E. Longobardi, M. C. Caselli, Cogn. Dev. 14, 57 (1999).

19. L. L. Namy, L. Acredolo, S. Goodwyn, J. Nonverbal Behav. 24, 63 (2000).

20. M. L. Rowe, S. Goldin-Meadow, Dev. Sci. 12, 182 (2009).

21. R. M. Baron, D. A. Kenny, J. Pers. Soc. Psychol. 51, 1173 (1986).

22. K. McCartney, M. R. Burchinal, K. L. Bub, Monogr. Soc. Res. Child Dev. 71, 88 (2006).

23. K. ]. Preacher, A. Hayes, Behav. Res. Methods Instrum. Comput. 36, 717 (2004).

24. L. M. Dunn, L. M. Dunn, Peabody Picture Vocabulary Test (American Guidance Service, Circle Pines, MN, ed. 3, 1997).

25. G. Butterworth, L. Grover, in Thought Without Language, L. Weiskrantz, Ed. (Carendon, Oxford, 1988), pp. 5-24.

26. M. Carpenter, K. Nagell, M. Tomasello, Monogr. Soc. Res. Child Dev. 63, 52 (1998).

27. J. M. Iverson, S. Goldin-Meadow, Psychol. Sci. 16, 367 (2005).

28. S. Goldin-Meadow, W. Goodrich, E. Sauer, J. Iverson, Dev. Sci. 10, 778 (2007).

29. S. C. Broaders, S. W. Cook, Z. Mitchell, S. Goldin-Meadow, J. Exp. Psychol. Gen. 136, 539 (2007).

30. S. W. Cook, S. Goldin-Meadow, J. Cogn. Dev. 7, 211 (2006).

31. Supported by the National Institute of Child Health and Human Development: grants K99HD055522 to M.L.R. and P01HD40605 to S.G.-M. We thank J. Huttenlocher, S. Levine, W. Meadow, J. Rowe, and three anonymous reviewers for comments on earlier versions; the families for their participation; K. Brasky, L. Chang, E. Croft, K. Duboc, ]. Griffin, S. Gripshover, K. Harden, L. King, C. Meanwell, E. Mellum, M. Nikolas, ]. Oberholtzer, C. Rousch, L. Rissman, B. Seibel, M. Simone, K. Uttich, and J. Wallman for data collection/transcription; E. Sauer for gesture coding; and K. Schonwald and J. Voigt for administrative/technical assistance.

\section{Supporting Online Material}

www.sciencemag.org/cgi/content/full/323/5916/951/DC1

Materials and Methods

SOM Text

References

9 October 2008; accepted 15 January 2009

10.1126/science.1167025 